\title{
SHYNESS DITINJAU DARI POLA ASUH OTORITER ORANG TUA PADA SISWA-SISWI SMA DI METHODIST-2 MEDAN
}

\author{
Sarinah, S.Psi, M.Psi \\ Fakultas Psikologi \\ Universitas Prima Indonesia
}

\begin{abstract}
This study aims to examine the relationship between the authoritarian parenting by parents and shyness. The hypothesis of this study is that there is a positive relationship between authoritarian parenting and shyness, assuming the higher the authoritarian parenting, the higher the shyness and conversely the lower the authoritarian parenting, the lower the shyness. Subjects of this study are tenth grade students of SMA Methodist-2 Medan as many as 240 people with cluster sampling method. Data are obtained from a scale to measure authoritarian parenting and shyness. The calculation is performed by assumption test that consists of normality test of distribution and linearity test of relationship. The data analysis used is product moment correlation through SPSS 17 for Windows. Results of the data analysis show a correlation coefficient of 0.882 with $p 0.000(p<0.05)$. The results show there is a positive relationship between authoritarian parenting and shyness. Authoritarian parenting is one of the factors that affect shyness by contribution (R2) of 77.8 percent and the remaining of 22.2 percent is affected by other factors not examined. In conclusion, the hypothesis of there is a positive relationship between the authoritarian parenting with shyness is accepted.
\end{abstract}

Keywords:Shyness; Parenting; Authoritarian Parenting

\section{PENDAHULUAN}

Setiap manusia pada hakekatnya pasti akan melalui tahapan perkembangan yang di mulai dari masa bayi, masa kanakkanak, masa remaja dan masa tua. Di dalam tahapan perkembangan tersebut tentu manusia akan mengalami proses belajar dari pengalamannya yang di dapat dari sekolah, keluarga dan lingkungan sosialnya karena manusia tercipta sebagai makhluk sosial. Sebagai makhluk sosial manusia sebagai individu senantiasa membutuhkan orang lain untuk saling berinteraksi satu dengan yang lainnya dan saling bersosialisasi.

Sebagian besar interaksi orang tua dan anak memiliki implikasi masa depan karena keluarga adalah tempat anak pertama kali mendapat pembelajaran mengenai cara berinteraksi dengan orang lain dan lingkungan sekitarnya. Remaja mendapatkan pembelajaran mengenai aturan, norma dan nilai-nilai yang ada di keluarga dan lingkungan dari cara pengasuhan orang tuanya Remaja akan belajar bagaimana melewati tahapantahapan kehidupan yang ada di dalam kehidupannya. Salah satu tahapan yang akan di lalui oleh setiap individu adalah pada fase masa remaja.

Papalia (2010) memaparkan bahwa masa remaja merupakan masa peluang sekaligus masa risiko. Para remaja berada dipertigaan antara kehidupan cinta, pekerjaan dan partisipasi dalam masyarakat dewasa. Masa remaja adalah 
masa dimana para remaja terlibat dalam perilaku yang menyempitkan pandangan dan membatasi pilihan mereka. Tahuntahun masa remaja merupakan masa dimana terjadi perubahan emosional, konflik dalam keluarga, perilaku tidak peduli dan penolakan terhadap nilai-nilai yang dimiliki oleh orang dewasa. Banyak remaja yang merasa sadar diri, malu, aneh, sendiri, gugup, atau diacuhkan. Emosi negatif dan perubahan suasana hati menjadi lebih intens pada masa awal remaja, dapat dikarenakan peristiwa menekan yang terkait dengan masa puber.

Buss (dalam Leitenbereg, 1990) menyatakan bahwa sifat pemalu muncul pada umur empat dan lima tahun, dan ketika anak bertumbuh menjadi remaja, maka sifat pemalu akan mencapai puncaknya pada umur 14-17 tahun. Oleh karena itu orang tua diharapkan dapat mengajarkan remaja mengenai kepercayaan diri dan cara bersosialisasi dengan lingkungan sekitarnya. Remaja memiliki kebutuhan untuk di bimbing dalam cara berinteraksi dan pembelajaran mengenai lingkungan sosial dari orang tuanya.

Remaja awal yang kurang diberikan pengarahan dan perhatian dari orang tuanya dapat tumbuh menjadi remaja yang pemalu karena merasa cemas dan takut dirinya tidak mampu untuk berinteraksi dengan lingkungan sosialnya. Shyness (pemalu) digambarkan oleh Cheek (dalam Leitenberg, 1990) sebagai sebuah kata yang biasanya diucapkan untuk menggambarkan perasaan gelisah dan perasaan tidak mampu berinteraksi dengan situasi sekitar.

Orang tua dalam mendidik anak memiliki gaya pengasuhan yang berbedabeda dimana, salah satu gaya pengasuhan yang diterapkan oleh orang tua kepada anak adalah pola asuh otoriter. Orang tua yang menerapkan gaya pengasuhan otoriter akan membuat aturan bahwa anak harus mengikuti semua perintah yang diberikan dan dibuat oleh orang tua. Anak akan tumbuh menjadi remaja yang bergantung pada orang tua dan tidak memiliki kepercayaan diri. Pola asuh yang mengekang tersebut akan membuat remaja berpikir bahwa dirinya tidak memiliki kemampuan untuk berinteraksi dengan lingkungan sekitarnya. Remaja secara tidak langsung akan tumbuh menjadi remaja yang mengalami shyness. Penelitian yang dilakukan Zarnaghash (2010) yang menyimpulkan adanya hubungan pola asuh otoriter orang tua dengan shyness pada remaja.

Baumrind (dalam Santrock, 2014) menjelaskan pola asuh otoriter adalah pola asuh yang bersifat kaku, membatasi dan menghukum. Orang tua yang otoriter 
mendesak anak-anak untuk mengikuti petunjuk dan menghormati orang tua. Orang tua menempatkan batasan yang tegas dan kontrol terhadap anak-anak mereka dan memungkinkan sedikit pertukaran verbal.

Berdasarkan uraian di atas yang berkaitan dengan shyness yang dialami remaja akibat pola asuh otoriter orang tua, maka peneliti tertarik untuk mengadakan penelitian mengenai "Shyness Ditinjau Dari Pola Asuh Otoriter Orang Tua Pada Siswa-Siswi SMA Di Methodist-2 Medan."

\section{KAJIAN PUSTAKA}

Eysenck (Rubin \& Coplan, 2010) mendefinisikan shyness sebagai sebuah sifat seorang individu yang berfokus kepada perasaan yang berhubungan dengan kesadaran diri, kekakuan dan kecemasan dalam interaksi sosial. Anakanak yang mengalami shyness tertarik untuk berinteraksi dengan lingkungan sosialnya, tetapi anak-anak tersebut takut dan cemas untuk memulai interaksi tersebut.

Asendorpf (dalam, Crozier \& Alden, 2001) berpendapat bahwa shyness adalah sebuah sikap antisipasi dari seorang individu yang mengalami ketidak sesuaian antara penilaian diri sendiri dengan penilaian dari orang lain, individu memiliki perasaan ketidakcocokan yang dirasakan dengan jelas antara dirinya dengan orang-orang lain yang ada di sekitarnya.

Menurut Crozier \& Alden (2008) memaparkan terdapat beberapa aspekaspek dari shyness, yaitu: (1) Pengalaman, mencakup ketakutan, ketegangan dan rasa kurang percaya diri; (2) Pengetahuan, diartikan sebagai ketidaktahuan individu dalam bersikap; (3) Kemampuan, individu tidak mampu untuk mengurangi sikap yang tidak memadai; (4) Kognisi, pemikiran tidak irasional sebelum, ketika menghadapi interaksi sosial, dan setelah berinteraksi dengan lingkungannya, individu akan menilai diri sendiri dengan penilaian yang negative; (5) Keadaan fisik, mencakup keadaan keringatan, gemetaran, dan pipi menjadi merah merona; (6) Perilaku menghindar, individu lebih memilih untuk menghindari interaksi sosial dan tidak memiliki kemampuan bersikap yang memadai sesuai dengan standar yang ada di lingkungan sekitar.

$$
\text { Adapun faktor-faktor yang }
$$

mempengaruhi shyness adalah: (1) Pola asuh orang tua. Pada penelitian yang dilakukan oleh D'Souza (2008) menunjukkan anak yang memiliki perasaan tidak nyaman dengan orang tuanya akan tumbuh menjadi remaja yang mengalami shyness. Anak yang memiliki 
kelekatan dengan orang tuanya akan merasakan kasih sayang dan perhatian dari orang tuanya. Namun ketika orang tua tidak konsisten memberikan kasih sayang dan perhatian kepada anak, orang tua akan gagal dalam memuaskan kebutuhan anak dalam merasa aman, kasih sayang, dan perasaan nyaman. Ketika kebutuhan akan kasih sayang anak tidak terpuaskan, anak akan merasa tidak nyaman dengan orang tua yang secara tidak langsung kelekatan antara orang tua dengan anak menjadi renggang; (2) Teman sebaya, memiliki peranan ketika remaja melakukan sosialisasi, lingkungan pertemanan dapat menjadi sebuah acuan bagi remaja dalam bersikap. Pada penelitian Bass (2010) ditemukan salah satu faktor yang mempengaruhi shyness dengan remaja awal adalah lingkungan. Kesepian adalah perasaan yang kerap dialami oleh para remaja. Kesepian yang dialami oleh remaja adalah hasil interaksi dari teman sebaya yang ada di lingkungan remaja. Lingkungan teman sebaya membuat remaja berani berinteraksi atau tidak berani berinteraksi sama sekali dengan lingkungannya. Remaja akan melihat lingkungan sekitarnya sebagai tempat yang dapat membuat dirinya nyaman untuk bersosialisasi jika teman sebayanya dapat menerima dirinya. Sedangkan remaja yang ditolak berinteraksi dengan lingkungan sosialnya akan cenderung merasa kesepian dan mengalami shyness; (3) Budaya. Pada penelitian yang dilakukan oleh Gudino (2010) terhadap anak-anak menunjukkan bahwa orang tua yang berlatar belakang budaya Amerika memiliki hubungan yang kurang baik dengan anaknya. Orang tua yang memiliki budaya Amerika jarang berkomunikasi dan berhubungan dengan anaknya yang membuat anak menjadi sulit untuk beradaptasi dengan lingkungannya dan mengalami shyness. Sedangkan orang tua yang memiliki latar budaya Inggris menunjukkan adanya komunikasi yang baik antara orang tua dengan anak yang membuat anak dapat bersosialisasi dengan baik di lingkungannya.

Papalia (2010) mendefinisikan pola asuh otoriter adalah pola asuh yang memandang penting kontrol dan kepatuhan tanpa syarat. Orang tua yang memiliki gaya pengasuhan otoriter akan mencoba membuat anak menyesuaikan diri dengan serangkaian standar perilaku dan menghukum anak dengan keras atas pelanggaran yang dilakukan anak. Anak akan cenderung menjadi menarik diri dari lingkungan dan tidak percaya kepada orang lain.

Robinson dkk (1995) menjelaskan pengukuran gaya pola pengasuhan otoriter orang tua ke dalam empat aspek: (1) 
Perkataan kasar, orang tua meluapkan amarah kepada anak menggunakan katakata yang kasar; (2) Hukuman fisik, orang tua menggunakan hukuman fisik sebagai cara untuk mendisiplinkan anak; (3) Tidak memberikan penjelasan, orang tua menghukum anak dengan cara menarik hak anak tanpa memberikan penjelasan kepada anak, (4) Mengarahkan, orang tua akan menuntut anak untuk bertindak sesuai dengan kemauan yang diinginkan oleh orang tua.

\section{METODE PENELITIAN}

Populasi dalam penelitian ini adalah siswa-siswi kelas X Methodist-2 Medan. Jumlah sampel yang diambil dalam penelitian ini adalah berjumlah 240 orang siswa-siswi. Pemilihan sampel pada penelitian ini adalah dengan menggunakan teknik cluster sampling.

Pengumpulan data dalam penelitian ini dilakukan dengan metode pembagian skala untuk mengukur hubungan pola asuh otoriter orang tua dengan shyness yang disusun dalam bentuk pernyataan dengan menggunakan skala likert. Pengujian skala dilakukan berdasarkan pengujian Validitas dan Uji Reliabilitas.

Analisis data menggunakan korelasi Product Moment untuk mengetahui bagaimana hubungan antara variabel pola asuh otoriter orang tua dengan shyness. Sebelum melakukan uji ini, terlebih dahulu dilakukan uji asumsi, yaitu uji normalitas sebaran dan uji linearitas hubungan, sebagai prasyarat sebelum dilakukan uji korelasi.

\section{HASIL DAN PEMBAHASAN}

Sebelum dilakukan analisis Product Moment, data yang terkumpul terlebih dahulu ditentukan sebaran dan linearitas hubungannya. Dari uji normalitas dan uji linearitas diketahui bahwa hasilnya memenuhi asumsi tersebut. Hasil uji normalitas sebaran dan uji linearitas hubungan dapat dilihat pada Tabel 1 dan Tabel 2 berikut ini:

Tabel 1.

Hasil Uji Normalitas

\begin{tabular}{|c|c|c|c|c|c|}
\multicolumn{1}{c|}{ Hasil Uji Normalitas } \\
\hline Variabel & SD & $\begin{array}{c}\text { K- } \\
\text { SZ }\end{array}$ & Sig & P & Ket \\
\hline Shyness & 10, & 0,6 & 0,4 & $\mathbf{P}>$ & Sebaran \\
& 714 & 34 & 08 & 0,05 & normal \\
\hline Pola Asuh & 10, & 0,7 & 0,3 & $\mathbf{P}>$ & Sebaran \\
Otoriter & 462 & 62 & 03 & 0,05 & normal \\
\hline
\end{tabular}

Data dikatakan berdistribusi normal jika p>0,05 (Priyatno, 2010). Uji normalitas yang dilakukan terhadap variabel shyness diperoleh koefisien KS-Z $=0,634$ dengan Sig sebesar 0,816 untuk uji 2 (dua) ekor dan Sig sebesar 0,408 untuk uji 1 (satu) ekor ( $\mathrm{p}>0,05)$, yang berarti bahwa data pada variabel shyness memiliki sebaran atau berdistribusi normal. Uji normalitas pada variabel pola asuh otoriter diperoleh koefisien KS-Z = 0,762 dengan Sig sebesar 0,606 untuk uji 2 (dua) ekor dan Sig sebesar 0,303 untuk 
uji 1 (satu) ekor ( $p>0,05)$. Berdasarkan hasil tersebut data pada variabel pola asuh otoriter memiliki sebaran atau berdistribusi normal karena $\mathrm{p}>0,05$.

Tabel 2. Hasil Uji Linearitas

\begin{tabular}{|c|c|c|c|}
\hline Variabel & F & P & Ket \\
\hline $\begin{array}{c}\text { Shyness } \\
\text { Pola Asuh } \\
\text { Otoriter }\end{array}$ & 776,433 & 0,000 & Linier \\
\hline \multicolumn{2}{|c|}{ Berdasarkan Tabel 2 dapat } \\
\hline
\end{tabular}

dikatakan bahwa variabel shyness dan pola asuh otoriter memiliki hubungan linear. Hal ini terlihat dari nilai $\mathrm{P}$ yang diperoleh yaitu 0,000 maka $\mathrm{p}<0,05$ maka dapat disimpulkan adalah kedua variabel memiliki hubungan linear dan telah memenuhi syarat untuk dilakukan analisa korelasi Product Moment.

Hipotesis dalam penelitian ini berbunyi bahwa ada hubungan positif antara pola asuh otoriter dengan shyness. Diasumsikan bahwa semakin tinggi pola asuh otoriter yang diterapkan orang tua, maka shyness pada remaja awal semakin besar, dan sebaliknya semakin rendah pola asuh otoriter yang diterapkan orang tua, maka shyness pada remaja awal semakin kecil.

Tabel 3.

Korelasi Antara Shyness dengan Pola Asuh Otoriter

\begin{tabular}{|c|c|c|}
\hline Analisis & $\begin{array}{c}\text { Pearson } \\
\text { Correlation }\end{array}$ & $\begin{array}{c}\text { Signifikansi } \\
(\mathbf{p})\end{array}$ \\
\hline Korelasi & 0,882 & 0,000 \\
\hline
\end{tabular}

Berdasarkan hasil analisis korelasi antara shyness dengan pola asuh otoriter, diperoleh koefisien korelasi product moment sebesar 0,882 dengan $\mathrm{p}$ sebesar $0,000$ ( $\mathrm{p}<0,05)$. Hal ini menunjukkan bahwa adanya korelasi positif antara shyness dengan pola asuh otoriter sehingga dikategorikan memiliki hubungan yang kuat (Priyatno, 2010).

Dari hasil perhitungan tersebut, maka hipotesis yang diajukan dalam penelitian ini menunjukkan ada hubungan positif antara pola asuh otoriter dengan shyness dapat diterima, dan dapat dinyatakan bahwa ada hubungan positif antara pola asuh otoriter dengan shyness.

Hasil penelitian pada 240 orang siswa-siswi kelas $\mathrm{X}$ yang bersekolah di Methodist-2 menjadi subjek penelitian maka diperoleh hasil bahwa ada hubungan positif antara pola asuh otoriter dengan shyness dengan koefisien korelasi sebesar $\mathrm{r}=0,882$, nilai $\mathrm{p}$ sebesar 0,000 , artinya semakin tinggi pola asuh otoriter yang diterapkan orang tua, maka shyness pada remaja awal semakin besar, dan sebaliknya semakin rendah pola asuh otoriter yang diterapkan orang tua, maka shyness pada remaja awal semakin kecil.

Tabel 4.

Model Summary Sumbangan Efektif

\begin{tabular}{|c|c|c|c|c|}
\hline Model & $\mathbf{R}$ & $\begin{array}{c}\mathbf{R} \\
\text { Square }\end{array}$ & $\begin{array}{c}\text { Adjusted } \\
\mathbf{R} \\
\text { Square }\end{array}$ & $\begin{array}{c}\text { Std. } \\
\text { Error of } \\
\text { the } \\
\text { Estimate }\end{array}$ \\
\hline 1 & $.882^{\mathrm{a}}$ & .778 & .777 & 5.060 \\
\hline
\end{tabular}

Berdasarkan Tabel 4 Model Summary Sumbangan Efektif di atas, 
dapat disimpulkan dalam penelitian ini diperoleh koefisien determinasi $R$ Square $\left(\mathrm{R}^{2}\right)$ sebesar 0,778. Berdasarkan hasil tersebut, dapat disimpulkan bahwa 77,8 persen pola asuh otoriter mempengaruhi shyness dan selebihnya 22,2 persen dipengaruhi oleh faktor lain. Adapun faktor lain yang mempengaruhi shyness pada remaja awal diantaranya seperti budaya dan lingkungan.

Dengan demikian, dapat disimpulkan bahwa semakin tinggi pola asuh otoriter yang diterapkan oleh orang tua, maka shyness yang dialami remaja awal semakin besar dan sebaliknya semakin rendah pola asuh otoriter yang diterapkan orang tua, maka shyness pada remaja awal juga semakin kecil.

\section{PENUTUP}

\section{Kesimpulan}

Berdasarkan hasil-hasil yang telah diperoleh dalam penelitian ini, maka dapat disimpulkan sebagai berikut: Ada hubungan positif antara shyness dengan pola asuh otoriter pada siswa-siswi Methodist-2 dengan korelasi Product Moment (r) sebesar 0,882 dengan $\mathrm{p}$ sebesar 0,000 ( $<<0,05)$, artinya semakin tinggi pola asuh otoriter yang diterapkan orang tua, maka shyness pada remaja awal akan semakin besar, dan sebaliknya jika semakin rendah pola asuh otoriter yang diterapkan orang tua, maka shyness pada remaja awal akan semakin kecil.

Hasil penelitian ini menunjukkan bahwa sumbangan yang diberikan variabel pola asuh otoriter terhadap shyness adalah sebesar 77,8 persen, selebihnya 22,2 persen dipengaruhi oleh faktor lain yang tidak diteliti seperti budaya dan lingkungan.

\section{Saran}

Berdasarkan kesimpulan yang telah dikemukakan, maka peneliti mengemukakan beberapa saran yang diharapkan akan berguna untuk kelanjutan studi korelasional ini. Saran bagi remaja, disarankan agar remaja dapat belajar untuk memiliki konsep diri yang positif dan belajar untuk meningkatkan kepercayaan diri agar terhindar dari shyness. Saran bagi orang tua, disarankan agar orang tua tidak menerapkan pola asuh otoriter guna menghindari remaja tumbuh menjadi remaja yang mengalami shyness. Saran kepada guru, disarankan agar guru dapat mendukung para siswasiswi untuk memiliki kepercayaan diri yang baik.

Saran kepada peneliti selanjutnya diharapkan dapat mencari faktor lain seperti budaya dan lingkungan yang dapat berpengaruh terhadap shyness dan lebih mengembangkan metode serta skala yang 
akan digunakan dalam penelitian sehingga

akan mendapatkan hasil yang lebih baik.

\section{DAFTAR PUSTAKA}

Crozier, W. R \& Alden. L. E. 2001. International Handbook of Social Anxiety.England.

Crozier, W. R \& Alden. L. E. 2008. Shyness and Embarrasment. NewYork: Cambridge University.

D'Souza, L, Urs, B,G, Jayaraju, R. 2008. Relationship Between Shyness and Guidance Needs Among Adolescents. Journal of the Indian Academy of Applied Psychology Vol. 34,

No.2, 317-322.

Gudino, O, G \& Lau, A, S. 2010. Parental Cultural Orientation, shyness, and anxiety in Hispanic Children: An Exploratory Study. Journal of Applied Development Psychology.

Leitenberg, H. 1990. Social and Evaluation Anxiety. New York: Plenum Press.

Papalia, D, E. 2010. Human Development (Psikologi Perkembangan). Jakarta: Kencana.

Priyatno, D. 2010. Teknik Mudah dan Cepat Melakuka Analisis Data Penelitian dengan SPSS dan Tanya Jawab Ujian Pendadaran. Yogyakarta: Gava Media.

Robinson, C, C, Mandleco, B, Olsen, F, S, Hart, H, C. 1995. Authoritative, Authoritarian, and Permissive Parenting
Practices: Development of a New Measure.

Rubin, K, H \& Coplan, R, J. 2010. The Development of Shyness and Social Withdrawl. New York.

Santrock, J. W.2014. Psikologi Pendidikan. Jakarta: Salemba Humanika.

Zarnaghash, M \& Samani, S. 2010. Study of The Effect of Family Pattern Styles on Shyness in Iranian Students. Jounal of Procedia Social and Behavioral Science. 